九州大学学術情報リポジトリ

Kyushu University Institutional Repository

\title{
Evaluation of Root Penetration Ability in Rice Using the Wax-Layers and the Soil Cake Methods
}

Nhan, Dang Quy

Graduate school of Bioresource and Bioenvironmental Sciences, Kyushu University

Thaw, Soe

Graduate school of Bioresource and Bioenvironmental Sciences, Kyushu University

Matsuo, Naoki

Graduate school of Bioresource and Bioenvironmental Sciences, Kyushu University

Xuan, Tran Dang

Faculty of Agriculture, University of Ryukyus

他

https://doi.org/10.5109/9237

出版情報: 九州大学大学院農学研究院紀要. 51 (2)，pp.251-256，2006-10-27. Faculty of Agriculture, Kyushu University

バージョン :

権利関係 : 


\title{
Evaluation of Root Penetration Ability in Rice Using the Wax-Layers and the Soil Cake Methods
}

\author{
Dang Quy NHAN ${ }^{1}$, Soe THAW ${ }^{1}$, Naoki MATSUO ${ }^{1}$, Tran Dang XUAN ${ }^{2}$, \\ Nguyen Huu HONG ${ }^{3}$ and Toshihiro MOCHIZUKI*
}

\author{
Laboratory of Agricultural Ecology, Division of Agricultural Ecology, Department of Plant Resources, \\ Faculty of Agriculture, Kyushu University, Fukuoka 811-2307, Japan \\ (Received June 30, 2006 and accepted July 24, 2006)
}

\begin{abstract}
Root penetration ability (RPA) is an important character of rice against drought stress. The development of screening techniques is an initial step to determine the RPA of rice varieties before introducing RPA related genes to improve drought resistant rice in breeding. A 3-wax-layers method was developed to evaluate the penetration ability of seminal roots in rice under dry soil conditions. The wax layer with $3 \mathrm{~mm}$ thickness and $6 \mathrm{~cm}$ in diameter was prepared by melting mixture of $60 \%$ paraffin and $40 \%$ vaseline, providing $1.5 \mathrm{MPa}$ of hardness at $25^{\circ} \mathrm{C}$. Three wax layers were installed tightly together in the tubes as the hardpans impeded the root growth. Rice seeds were sown in a randomized complete block design with three replications in a growth chamber at $25^{\circ} \mathrm{C}$. Root penetration rate (RPR) refers to RPA was measured as the ratio of the number of the seminal roots (SRN) that penetrated the wax layer(s) (1, 2 or 3 wax layer(s)) to the total SRN. Simultaneously, another experiment using the soil cakes (9 mm thickness, 1.5 MPa of hardness, and $13 \%$ soil moisture content) was conducted to compare with the wax layer method. As a result, RPR through 3 wax layers (RPR3W) had significant positive correlation with that through the soil cake $\left(r=0.68^{* *}\right)$. We suggest that, the use of 3 -wax-layers could be more effective to estimate RPA than the common use of the $3 \mathrm{~mm}$ wax layer. Japonica upland rice showed greater RPR than the other groups. The impeded seminal root showed an increase in root diameter compare to the roots grown in non-impeded soil conditions. In response to the impedance, tend to increase its diameter linked with RPA.
\end{abstract}

\section{INTRODUCTION}

Drought stress is a major cause of low yield of rice grown in the rainfed lowland and upland (Khush, 1997) which accounts for about $25 \%$ of the world's rice-cultivated area, but where in Asia, the average grain yield is only 2.3 ton ha ${ }^{-1}$ (IRRI, 1997). In rainfed lowland, fields are alternating by flooding and drying, therefore the rooting zone is subject to anaerobic and aerobic conditions, depending on the rainfall (Sharma, 1995). Shallow hardpans are very common in the rainfed lowland and appear to impede root penetration (Kundu et al., 1996; Wade et al., 1999).

In upland, soils are commonly aerobic and could strong due to lack of water. Strong soil can be a serious problem in rice production as it can restrict access of the root system to water and nutrients (Clark et al., 2003). Rice plant with a deep root system is therefore beneficial in avoiding water stress by absorbing water from deep soil layers (Clark et al., 2002). Root penetration ability (RPA) through compacted soil layers or hardpans has been recognized as an important for improvement of drought resistance in rice (Hanson et

${ }^{1}$ Laboratory of Agricultural Ecology, Division of Agricultural Ecology, Department of Plant Resources, Graduate school of Bioresource and Bioenvironmental Sciences, Kyushu University.

${ }^{2}$ Faculty of Agriculture, University of the Ryukyus, Okinawa, Japan

${ }^{3}$ Faculty of Agronomy, Thai Nguyen University of Agriculture and Forestry, Thai Nguyen, Vietnam

* Corresponding author (E-mail: mochizuki@farm.kyushu-u. ac.jp) al., 1990)

Several screening techniques for RPA in both laboratory and field conditions have been conducted. Field screening can reflect accurately the ability of rice root penetration in natural conditions, however it requires heavy field work, wide area, costly and can not evaluate many rice cultivars at the same time. However, laboratorial screenings are more convenient, limit these shortage of field screenings and can be conducted year round (Xuan et al., 2004). Yu et al. (1995) published a laboratorial method that used wax layers to screen rice varieties for root penetration. They found that upland rice varieties had better RPA than lowland ones, using 3 $\mathrm{mm}$ of the wax layers (60\% wax : 40\% petrolatum white). This method was subsequently used by several researchers (Ali et al., 2000; Babu et al., 2003; Price et al., 2000; Ray et al., 1996; Zheng et al., 2000) to identify QTLs controlling root penetration. During assessment and further development of the wax layers method, Clark et al. (2000) found that, rankings between cultivars could be very sensitive to screening conditions an criteria. RPA was assessed either as the number of root penetrating the strong wax layer, or as a proportion of the roots that penetrated a low impedance control. Another method for screening RPA was introduced by Tanakamaru et al. (1998). The artificial soil cakes (1.5 MPa of hardness and $1 \mathrm{~cm}$ thickness) were used to examine the penetration of seminal root in cereal and tap root in leguminous crops.

Both the wax layers and the soil cakes methods were considerably effective in screening RPA. In many previous researches, the single wax layer of $3 \mathrm{~mm}$ in thickness was commonly used and was installed in 
flooded condition to screen crown roots of rice (Ali et al., 2000; Babu et al., 2001; Clark et al., 2000; Ray et al., 1996; Yu et al., 1995; Zheng et al., 2000). The soil cake was considered similar to natural hardpans (Tanakamaru et al., 1998). However, the relationships between the wax layers and the soil cakes methods have not been reported. In this research, a 3-wax-layers system was developed to investigate the varietal differences on RPR of rice seminal root. Soil cakes method was used as control to compare with the 3-wax-layers method. Furthermore, we applied 3-wax-layers method to evaluate the penetration ability of seminal root at early stage in 30 rice cultivars collected from Vietnam and other countries.

\section{MATERIALS AND METHODS}

\section{Plant materials}

Thirty rice varieties were used (Table 1). Eight were Vietnamese traditional upland, 5 were Indica upland derived from International Rice Research Institute (IRRI) and several other countries, 10 were Japanese inbred upland, and 7 were lowland, of which 6 were from Japan and another was from U. S. A.

\section{Preparation of the wax layers and soil cakes}

The wax layers with different hardness were prepared by mixing paraffin and vaseline in different proportions. The mixture of six paraffin portions (30, 40, 50, 60, 70 and 80\%) and vaseline was well blended. It was heated at $80^{\circ} \mathrm{C}$ until the wax was completely melted. The mixture was then poured into polyvinyl chloride (PVC) tubes (height: $70 \mathrm{~mm}$ or $3 \mathrm{~mm}$, diameter: $6 \mathrm{~cm}$ ) and allowed to solidify at room temperature. The strength of wax layers of $70 \mathrm{~mm}$ thick was measured at $25^{\circ} \mathrm{C}$ by a penetrometer (DIK-5561, Daikirikakogyo Co., Ltd. Japan).

The soil cake $(9 \mathrm{~mm}$ of thickness and $96 \mathrm{~mm}$ in diameter) was prepared as described by Takanamaru et al. (1998). It was made by an oil pressure pump, and an apparatus to make the soil cakes (Fig. 1). The apparatus is a round steel frame (inner diameter: $96 \mathrm{~mm}$, outer diameter: $120 \mathrm{~mm}$, height: $90 \mathrm{~mm}$ ) with closed bottom. This frame is easy to separate into two pieces. There are 3 similar separated steel plates (diameter: $96 \mathrm{~mm}$, height: $5 \mathrm{~mm}$ ) and another bigger steel plate (diameter: $96 \mathrm{~mm}$, height: $30 \mathrm{~mm}$ ). The soil cake was prepared as follows: (i) the air-dried paddy soil was sieved through a $2.54 \mathrm{~mm}$ screen, and transferred into a drying oven set at $80^{\circ} \mathrm{C}$ for $72 \mathrm{~h}$. The soil was cooled at room temperature and was balanced the moisture to about $13 \%$ by volume. Then the soil was kept in closed plastic container until use; (ii) an amount of $115 \mathrm{~g}$ of the soil (13\% moisture content) was placed into the frame and the steel plate (5 mm in height) was put on it. Three similar amount of soil were combined to be 3 soil cakes at once. Finally, the $30 \mathrm{~mm}$ plate was put on the top of the third soil layer, and was pressed by the pump.

Soil cake strength of each treatment was measured using a soil penetrometer as described in the wax layers method. The data collected was the average of 3 replications for each treatment.

\section{Three-Wax- layers experiment}

The wax layers of $3 \mathrm{~mm}$ in thickness with $60 \%$ paraffin were used. Three wax layers were installed tightly together at $2 \mathrm{~cm}$ from the top of a PVC tube (height:

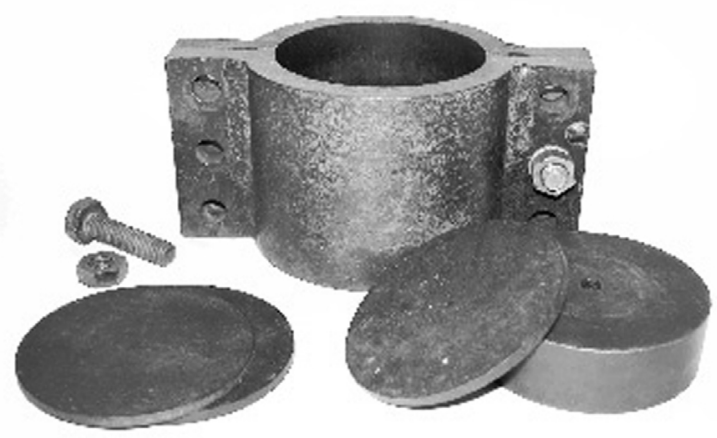

Fig. 1. The apparatus to make soil cakes: A round steel frame (inner diameter: $96 \mathrm{~mm}$, outer diameter: $120 \mathrm{~mm}$, height $90 \mathrm{~mm}$ ). Three separated steel plate (diameter: $96 \mathrm{~mm}$, height: $5 \mathrm{~mm}$ ) and another bigger steel plate (diameter: $96 \mathrm{~mm}$, height: $30 \mathrm{~mm})$.

Table 1. Plant materials and origins

\begin{tabular}{|c|c|c|c|c|c|}
\hline Name & Variety type & Origins & Name & Variety type & Origins \\
\hline Beo dien & Traditional Upland & Vietnam & Rikuto Norin 24 & Japanese Inbred Upland & Japan \\
\hline Ep hat dai & Traditional Upland & Vietnam & Rikuto Norin Mochi 6 & Japanese Inbred Upland & Japan \\
\hline Ep hat den & Traditional Upland & Vietnam & Rikuto Norin Mochi 8 & Japanese Inbred Upland & Japan \\
\hline Khau ken & Traditional Upland & Vietnam & Rikuto Norin Mochi 18 & Japanese Inbred Upland & Japan \\
\hline Khau linh & Traditional Upland & Vietnam & Rikuto Norin Mochi 20 & Japanese Inbred Upland & Japan \\
\hline Khau kai & Traditional Upland & Vietnam & Rikuto Norin Mochi 25 & Japanese Inbred Upland & Japan \\
\hline Nep bao lac & Traditional Upland & Vietnam & Hataminori Mochi & Japanese Inbred Upland & Japan \\
\hline Nep khau non & Traditional Upland & Vietnam & Owarihata Mochi & Japanese Inbred Upland & Japan \\
\hline IR57920 & Upland & IRRI & Lemont & Lowland & U. S. A \\
\hline IR71525-19-1-1 & Upland & IRRI & Akebono & Lowland & Japan \\
\hline UPLR 1-7 & Upland & IRRI & Akenohoshi & Lowland & Japan \\
\hline IRAT 117 & Upland & Ivory coast & Koshihikari & Lowland & Japan \\
\hline Azucena & Upland & Philippines & Shinriki & Lowland & Japan \\
\hline Rikuto Norin 12 & Japanese Inbred Upland & Japan & Norin 18 & Lowland & Japan \\
\hline Rikuto Norin 22 & Japanese Inbred Upland & Japan & Houyoku & Lowland & Japan \\
\hline
\end{tabular}


$7 \mathrm{~cm}$, diameter: $6 \mathrm{~cm}$ ) as in Fig. 2. The gaps between wax layers and the side of the tube were sealed by melted wax. The remaining space in the tube was filled with soil of $13 \%$ moisture content. These tubes were placed in a plastic container (15 tubes per container) and were covered by plastic wrap to prevent water from evaporating. Seeds were soaked in distilled water and incubated at $30^{\circ} \mathrm{C}$ for 3 days. Then 10 seeds in each variety were sown on the top of the wax layer of the tube. Seedlings were grown in dark conditions at $25^{\circ} \mathrm{C}$.

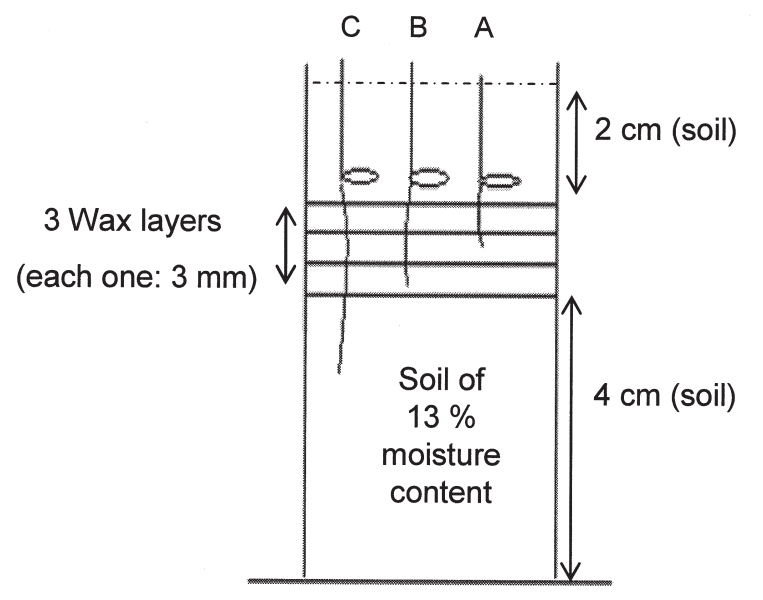

Fig. 2. Three-wax-layers system:
A. Root penetrated 1 wax layer
B. Root penetrated 2 wax layers
C. Root penetrated 3 wax layers.

The number of germinated seeds and the number of seminal roots (SRN) completely penetrated the $3^{\text {rd }}$ wax layer was counted at 7 days after seeding (DAS). Then, the third wax layer was separated gently by using a cutter (without breaking the roots) and SRN that completely penetrated the $2^{\text {nd }}$ wax layer was counted. Afterwards, the $2^{\text {nd }}$ wax layer was also removed without any damage to the roots and SRN that penetrated the $1^{\text {st }}$ wax layer could therefore count. Finally, all roots have been separated from the wax layer and were cleaned. RPR through each wax layer was determined by the ratio of SRN completely penetrated through each wax layer to the total SRN. Root thickness was measured at $1 \mathrm{~cm}$ from the root tip using an ocular micrometer of a microscope. Seminal root length was measured from root base to root tip.

In another trial, we conducted a test of root length and root thickness of all rice varieties in the plastic tube without wax layer.

\section{Soil cakes experiment}

The soil cakes were made by oil pressure pump. The pressure of $5.1 \mathrm{~kg} \mathrm{~cm} \mathrm{~cm}^{-2}$ was used to make the soil cakes $(1.5 \mathrm{MPa}, 9 \mathrm{~mm}$ in thickness and $96 \mathrm{~mm}$ in diameter). Three soil cakes were then transferred to a plastic container ( $15 \mathrm{~cm}$ width, $30 \mathrm{~cm}$ length and $20 \mathrm{~cm}$ depth), which already covered by a $5 \mathrm{~cm}$ depth of soil (13\% moisture content). The soil cakes then were covered with a $2 \mathrm{~cm}$ depth of the same soil. Seeds were soaked in distilled water and incubated at $30^{\circ} \mathrm{C}$ for 3 days. Ten seeds in each variety were sown just above the top of each soil cake. Seedlings were grown in the dark room at $25^{\circ} \mathrm{C}$. At $7 \mathrm{DAS}$, the number of seedlings were counted. SRN that completely penetrated through the soil cake was counted. RPR was evaluated as the ratio of SRN that completely penetrated through the soil cake to the total SRN.

\section{Data analysis}

All treatments of the study were arranged in a randomized complete block design with three replications. Data were analyzed with the statistical procedures of SAS version 6.12 (SAS Institute, Cary, NC,) using PROC ANOVA procedure, and correlations were obtained with the PROC CORR procedure (Pearson correlations).

\section{RESULTS}

\section{The strength of the wax layers and soil cakes}

Penetrometer resistance was proportional to percentage of paraffin in the wax layers, reaching $4.5 \mathrm{MPa}$ at $80 \%$ paraffin (Fig. 3). In the previously study, the wax layer with $1.47 \mathrm{MPa}$ of hardness was used to screen $\mathrm{RPA}$ in rice (Yu et al., 1995). In this experiment, the wax layer with $60 \%$ of paraffin concentration showed 1.5 MPa of hardness. The strength of the soil cake in different level of the pressure of the oil pump was also

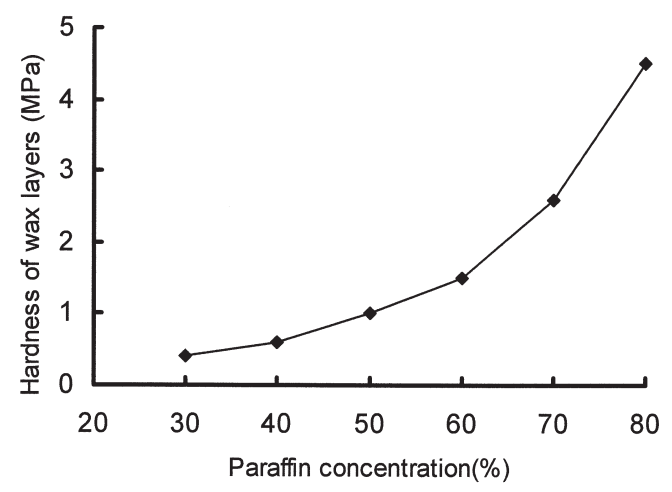

Fig. 3. Effect of paraffin concentration on hardness of wax layers.

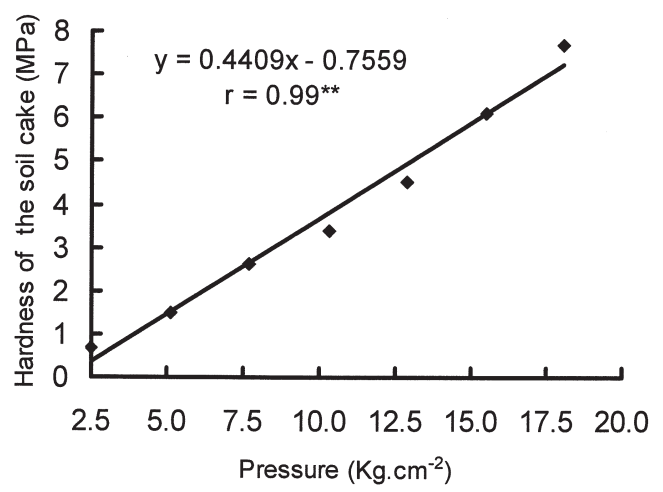

Fig. 4. Relationship between pressure of the pump to make the soil cake and hardness of soil cake; ** Significant at P = 0.01 . 
observed (Fig. 4). The relationship between the pressure of the oil pump and the hardness of soil cakes was linear $(r=0.99 * *)$. The strength of soil cakes was increased from $0.7 \mathrm{MPa}$ to $7.7 \mathrm{MPa}$ when the pressure of the oil pump extended from $2.5 \mathrm{~kg} \mathrm{~cm} \mathrm{~cm}^{-2}$ to $18.1 \mathrm{~kg} \mathrm{~cm}^{-2}$ (Fig. 4). At $5.1 \mathrm{~kg} \mathrm{~cm}^{-2}$ of the pressure, the hardness of the soil cake showed 1.5 MPa.

\section{Relationship between RPA in the soil cakes and the wax layers methods}

In order to identify the penetration of seminal root among rice cultivars, we used RPR criterion referred to RPA. There was a low correlation between RPR of the soil cake and that of the 1 wax layer $\left(r=0.38^{*}\right)$ (Fig. 5-A). Through the soil cake, a large difference among RPR of screened cultivars (0-93.3\%) was observed. While RPR through the 1 wax layer were ranged from 43.3 to $100 \%$. RPR through the 2 wax layers were ranged from 23.3 to $92.6 \%$ (Fig. 5-B), and that through the 3 wax layers varied from 0 to $80.0 \%$ (Fig. 5-C).
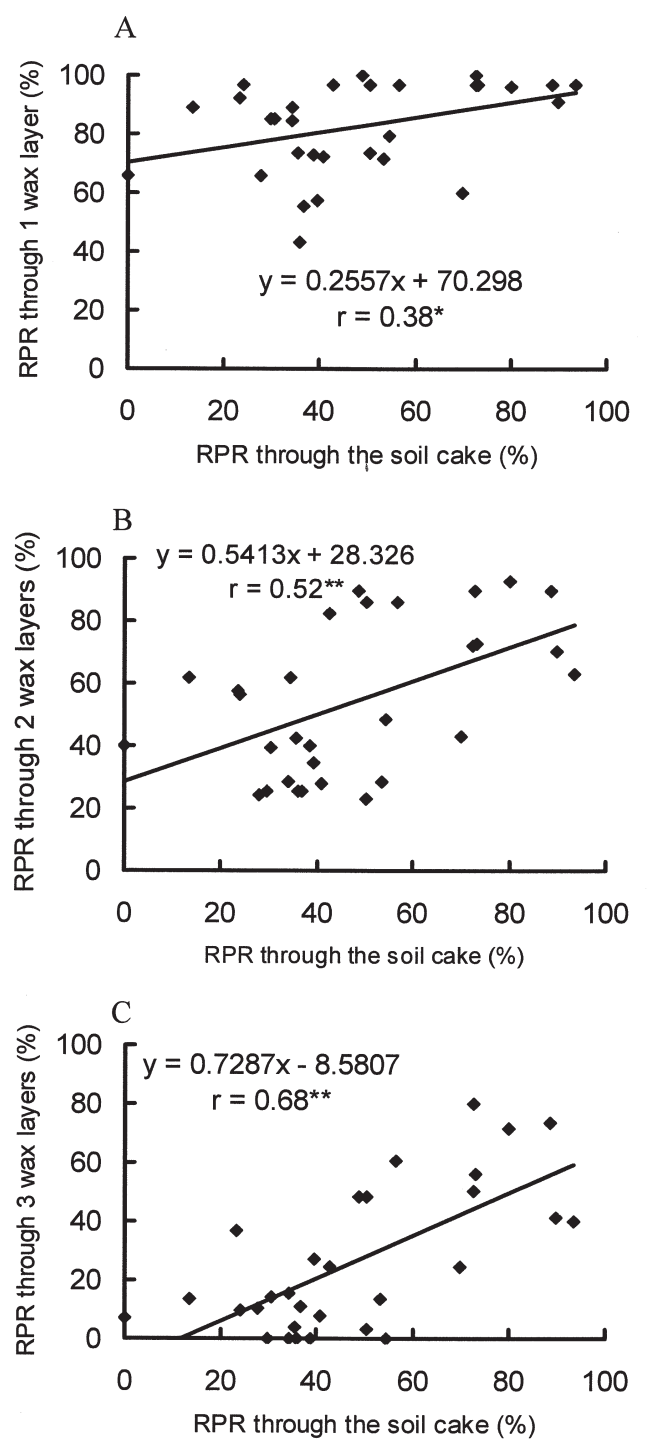

Fig. 5. Relationship between root penetration rate through the soil cake and that through: A. One wax layer; B. Two wax layers; C. Three wax layers; *, ** Significant at $\mathrm{P}=0.05$ and $\mathrm{P}=0.01$, respectively.
There were significant positive correlation between RPR through 2 and 3 wax layers and that through the soil cake $\left(r=0.52^{* *}\right.$ and $r=0.68^{* *}$, respectively).

\section{Genotypic variation of RPR among rice cultivars}

In the 3-wax-layers method, we found that RPR of Japanese inbred upland rice was superior to that of the other cultivars, which varied from 40 to 80\% (Fig. 6). Japanese inbred varieties included 6 varieties with RPR of $(40-<60 \%), 3$ varieties had RPR of $(60-<80 \%)$, and 1 variety with $\mathrm{RPR}$ reached $80 \%$. In contrast, most Vietnamese traditional upland, IRRI upland and lowland rice varieties showed low RPR, which was not exceeded 40\%. Seven Vietnamese traditional upland, 4 upland of IRRI and 5 lowland rice varieties had RPR lower than $20 \%$.

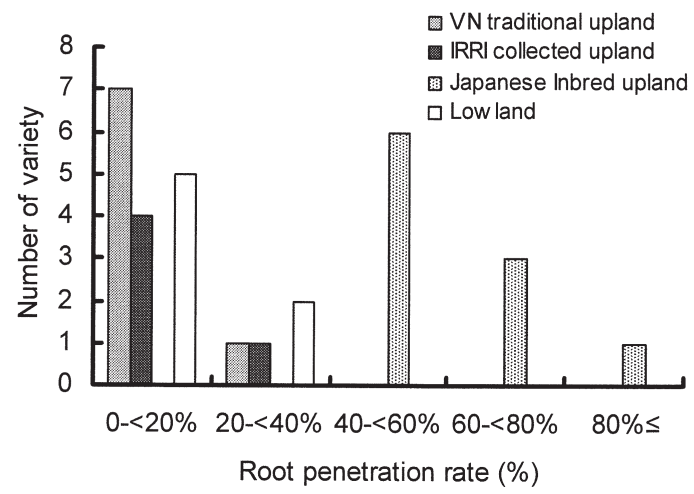

Fig. 6. Varietal difference in root penetration rate through 3 wax layers.

\section{Relationship between RPR and some root traits.}

The mean and range of root thickness (RTW), root length (RLW) in tube with hardpan, and root thickness (RTWO), root length in tube without hardpan (RLWO) are summarized in the Table 2. RLWO value was higher than RLW (ranged from 48.4 to $120 \mathrm{~cm}$ and from 48.2 to $112.4 \mathrm{~cm}$, resectively). However, the RTWO was lower than RTW (ranged from 0.16 to $0.46 \mathrm{~mm}$ and from 0.23 to $0.80 \mathrm{~mm}$, respectively).

Table 2. Range and mean of root thickness and maximum root length in 2 treatments

\begin{tabular}{ccr}
\hline Trait & Range & \multicolumn{1}{c}{ Mean $^{1}$} \\
\hline RTW & $0.23-0.80$ & $0.52 \pm 0.03$ \\
RTWO & $0.16-0.46$ & $0.33 \pm 0.02$ \\
RLW & $48.2-112.4$ & $78.0 \pm 3.05$ \\
RLWO & $48.4-120.6$ & $89.76 \pm 3.47$ \\
\hline
\end{tabular}

${ }^{1}$ Mean valuest SE.

Significant correlation coefficient was existed among the rice accessions between RPR and some root traits (Table 3). RPR through 3 wax layers (RPR3W) had a significant positive correlation with RLW and RLWO ( $\mathrm{r}=0.63^{* *}$ and $\mathrm{r}=0.54^{* *}$, respectively). RPR3W and RTW had a significant positive correlation ( $\mathrm{r}=$ $\left.0.75^{* *}\right)$. However, the RPR3W had negative correlation with RTWO $\left(r=0.59^{* *}\right)$. The relationship between RLW 
Table 3. Correlation coefficient among root penetration rate, root length and root thickness

\begin{tabular}{cccccc}
\hline & RPR3W & RLW & RLWO & RTW & RTWO \\
\hline RPR3W & - & $0.63^{* *}$ & $0.54^{* *}$ & $0.75^{* *}$ & $-0.59^{* *}$ \\
RLW & & - & $0.91^{* *}$ & $0.76^{* *}$ & $-0.26 \mathrm{~ns}$ \\
RLWO & & & - & $0.68^{* *}$ & $-0.26 \mathrm{~ns}$ \\
RTW & & & & - & $-0.44^{*}$ \\
RTWO & & & & & - \\
\hline
\end{tabular}

*, ** Significant at $\mathrm{P}=0.05$ and $\mathrm{P}=0.01$, respectively; ns: not significant.

and RLWO had a positive correlation coefficient ( $\mathrm{r}=$ $0.91^{* *}$ ). RTW had positive correlation coefficient with both RLW and RLWO $\left(\mathrm{r}=0.76^{* *}\right.$ and $\mathrm{r}=0.68^{* *}$, respectively). While the negative correlation coefficient between RTW and RTWO was detected $\left(r=-0.44^{* *}\right)$.

\section{DISCUSSION}

Among attempts to develop appropriate screening methods of RPA, several previous researches conducted by using wax-layers. However, these models applying the wax layer should be further modified to receive the actual RPA of rice cultivars under field conditions. The first application of the wax layer for screening PRA was conducted by Taylor and Gardner (1960). Then the wax layers system was developed to screen genotypic variation on RPA of rice (Yu et al., 1995). They reported that the rice cultivars from dryland hydrological origins had greater RPA than cultivars from wetland origins. However, the effect of wax layer thickness has not been documented so far. Using the same method, Babu et al. (2001) suggested that indica accessions and traditional rice had superior root-and shoot-related drought resistance traits. Wax layers were subsequently used to identify QTLS for root penetration and root traits in rice (Ali et al., 2000; Ray et al., 1996; Zheng et al., 2000). In our experiment, low variation of RPR through 1 wax layer among rice cultivars was observed. Moreover, correlation coefficient between RPR though the soil cake and that through 1 wax layer was low $\left(r=0.38^{*}\right.$ ) (Fig. 5-A). The genotypic difference of RPA between strong and weak varieties was ambiguous. For example, RPR through the soil cake among varieties ranged from 0 to $100 \%$ was higher than that in 1 wax layer ranged from 43.3 to $100 \%$. This evidence showed that by using 1 wax layer, the varietal difference in RPA was not identified. The result in Fig. 5-C showed that, a high positive correlation coefficient between RPR through the soil cake and that through 3 wax layers was detected $\left(r=0.68^{* *}\right)$. The Japanese inbred upland varieties were found to have good penetration ability (Fig. 6). All varieties had RPR through 3 wax layers more than 40\% (Fig. 5-C). Findings of our study revealed that the use of $9 \mathrm{~mm}$ thickness wax layers were more efficient to access PRA than using $3 \mathrm{~mm}$ thickness wax layers.

RPA in compacted soil is an important breeding target to improvement of drought tolerance in crops
(Babu et al., 2001; Hanson et al., 1990; Samson et al., 2002). Recent advance techniques in molecular biology and molecular linkage maps of rice may enhance the approach to new rice varieties with strong drought tolerance. Molecular markers linked to RPA and mapping QTLs for root traits (Ali et al., 2000; Ray et al., 1996; Zheng et al., 2000). However, screening techniques to evaluate correctly the actual PRA of rice in a short time, less expensive, possible to conduct year round and on many rice cultivars are the priority before a breeding program starts.

Root thickness is considered as an important root characteristic contributing to drought resistance (Ekanayake et al., 1985). Thick root have larger xylem vessels, persist longer, produce more and larger branch roots and there by increase root length density and water uptake capacity in rice (Ekanayake et al., 1985; Ingram, 1994). Root thickness appears to have a positive association with RPA. Consequently, in practice, root systems must be able to enter and grow through hardpans of drought-hardened soils, in order to capture resources from deeper soil layers. Commonly, drought-resistant dryland rice cultivars had thicker roots than other rice cultivars (Nguyen et al., 1997; Samson et al., 2002; Yu et al., 1995). Yoshida (1982) postulated that thick roots were associated with deep root systems. Studies by Materechera et al. (1992) and Ray et al. (1996) denoted that thicker roots had greater penetration ability. Veen (1982) suggested that when they compared with roots growth in a nutrient solution, the impeded crown roots showed a reduction in length of about $75 \%$ whereas the diameter was about $50 \%$ increase. The increase in root thickness in response to impedance is caused by cortical cells enlarging radially rather than axially, with a corresponding change in the orientation of the cellulose microfibrils in the cell walls. It is also suggested that ethylene acts an intermediate factor in the effect of mechanical impedance on root growth.

In this study, seminal roots were measured for the root thickness and maximum root length with and without hardpan at 7 DAS. Mean value of RTW was bigger than the RTWO (0.52 mm and $0.33 \mathrm{~mm}$, respectively) (Table 2). The relationship between RTW and RPR3W had positive correlation coefficient $\left(r=0.75^{* *}\right)$ (Table 3). However, RTWO had a negative correlation coefficient with RPR3W ( $\mathrm{r}=-0.59^{* *}$ ) (Table 3$)$. Based upon these findings, we may conclude that the ability of rice root to reach deep soil moisture or to penetrate compacted soil is linked with the capacity to develop a root thickness.

\section{REFERENCES}

Ali, M. L., M. S. Pathan, J. Zhang, G. Bai, S. Sarkarung and H. T. Nguyen 2000 Mapping QTLs for root traits in a recombinant inbred population from two indica ecotypes in rice. Theoretical and Applied Genetics, 101: 756-766

Babu, R. C., B. D. Nguyen, V. Chamarerk, P. Shanmugasundaram, P. Chezhian, P. Jeyaprakash, S. K. Ganesh, A. Palchamy, S. Sadasivam, S. Sarkarung, L. J. Wade and H. T. Nguyen 2003 
Genetic analysis of drought resistance in rice by molecular markers: Association between secondary traits and field performance. Crop Sci, 43: 1457-1469

Babu, R. C., H. E. Shashidhar, J. M. Lilley, N. D. Thanh, J. D. Ray, S. Sadasivam, S. Sarkarung, J. C. O'Toole and H. T. Nguyen 2001 Variation in root penetration ability, osmotic adjustment and dehydration tolerance among accessions of rice adapted to rainfed lowland and upland ecosystems. Plant Breeding, 120: 233-238

Clark, L. J., S. L. Aphale and P. B. Barraclough 2000 Screening the ability of rice roots to overcome the mechanical impedance of wax layers: importance of test conditions and measurement criteria. Plant Soil, 219: 187-196

Clark, L. J., R. E. Cope, W. R. Whalley, P. B. Barraclough and L. J. Wade 2002 Root penetration of strong soil in rainfed lowland rice: comparison of laboratory screens with field performance. Field Crop Res, 76: 189-198

Clark, L. J., W. R. Whalley and P. B. Barraclough 2003 How do roots penetrate strong soil? Plant Soil, 255: 93-104

Ekanayake, I. J., J. C. Otoole, D. P. Garrity and T. M. Masajo 1985 Inheritance of Root Characters and Their Relations to Drought Resistance in Rice. Crop Sci, 25: 927-933

Hanson, A. D., W. J. Peacock, L. T. Evans, C. J. Arntzen and G. S. Khush 1990 Drought Resistance in Rice. Nature, 345: $26-27$

Ingram, K. T., F. D.Bueno, O. S. Namuco, E. B. Yambao and C. A. Beyrouty 1994 Rice root traits for drought resistance and their genetic variation. P. 67-77. In G. J. D. Kirk (ed) Rice roots: Nutrient and water use. IRRI, Manila. Philippines., P. $67-77$

IRRI 1997 IRRI Rice Almanac, 2nd Edition. International Rice Research Institute, Losbanos, Philippines.

Kamoshita, A., J. X. Zhang, J. Siopongco, S. Sarkarung, H. T. Nguyen and L. J. Wade 2002 Effects of phenotyping environment on identification of quantitative trait loci for rice root morphology under anaerobic conditions. Crop Sci, $\mathbf{4 2}$ : $255-265$

Khush, G. S. 1997 Origin, dispersal, cultivation and variation of rice. Plant Molecular Biology, 35: 25-34

Kundu, D. K., J. K. Ladha and E. LapitandeGuzman 1996 Tillage depth influence on soil nitrogen distribution and availability in a rice lowland. Soil Sci Soc Am J, 60: 1153-1159

Materechera, S. A., A. M. Alston, J. M. Kirby and A. R. Dexter 1992 Influence of Root Diameter on the Penetration of Seminal Roots into a Compacted Subsoil. Plant Soil, 144: 297-303
Nguyen, H. T., R. C. Babu and A. Blum 1997 Breeding for drought resistance in rice: Physiology and molecular genetics considerations. Crop Sci, 37: 1426-1434

Pantuwan, G., S. Fukai, M. Cooper, S. Rajatasereekul and J. C. O'Toole 2002 Yield response of rice (Oryza sativa L.) genotypes to different types of drought under rainfed lowlands-Part 3. Plant factors contributing to drought resistance. Field Crop Res, 73: 181-200

Price, A. H., K. A. Steele, B. J. Moore, P. B. Barraclough and L. J. Clark 2000 A combined RFLP and AFLP linkage map of upland rice (Oryza sativa L.) used to identify QTLs for root-penetration ability. Theoretical and Applied Genetics, 100: $49-56$

Ray, J. D., L. Yu, S. R. McCouch, M. C. Champoux, G. Wang and H. T. Nguyen 1996 Mapping quantitative trait loci associated with root penetration ability in rice (Oryza sativa L). Theoretical and Applied Genetics, 92: 627-636

Samson, B. K., M. Hasan and L. J. Wade 2002 Penetration of hardpans by rice lines in the rainfed lowlands. Field Crop Res, 76: $175-188$

Sharma, P. K., K. T. Ingram, D. Harnpichitvitaya 1995 Subsoil copaction to improve water use efficiency and yields of trainfed lowland rice in coarse-textured soils. soil Tillage Res., 36: 33-44

Tanakamaru, S., T. Mochizuki, S. Hayashida and T. Furuya. 1998 Specific difference in root penetration into the compacted soil cakes in crop plants. Jpn. J. Crop Sci., 67

Taylor, H. M., and H. R. gardner 1960 Use of wax substrates in root penetration studies. Soil Sci. Soc. Am. Proc., 24: 79-81

Wade, L. J., S. Fukai, B. K. Samson, A. Ali and M. A. Mazid 1999 Rainfed lowland rice: physical environment and cultivar requirements. Field Crop Res, 64: 3-12

Xuan, T. D., T. Eiji, T. Shinkichi and T. D. Khanh 2004 Methods to determine allelopathic potential of crop plants for weed control. Allelopathy J, 13: 149-164

Yoshida, S. H. 1982 The rice root systems: its development and function. In: Drought resistance in crop with emphasis on rice. International Rice Research Institute. Lobanos, Philippines., 97-114

Yu, L. X., J. D. Ray, J. C. Otoole and H. T. Nguyen 1995 Use of Wax-Petrolatum Layers for Screening Rice Root Penetration. Crop Sci, 35: 684-687

Zheng, H. G., R. C. Babu, M. S. Pathan, L. Ali, N. Huang, B. Courtois and H. T. Nguyen 2000 Quantitative trait loci for root-penetration ability and root thickness in rice: comparison of genetic backgrounds. Genome, 43: 53-61 